\title{
Elearn: Towards a Collaborative Educational Virtual Environment
}

\author{
Anna Michailidou \& Anastasios A. Economides \\ University of Macedonia, Thessaloniki, Greece
}

\section{annamich@in.gr economid@uom.gr}

\section{Executive Summary}

The evolving growth in networking and telecommunication technologies leads to their enhanced usage in many and different aspects of human activity. One of the technologies that shows great interest is Collaborative Virtual Environments (CVEs), which may be used in various applications, such as tele-education. This paper presents, analyzes and evaluates the basic elements of Elearn, a Collaborative Virtual Learning Environment (CVLE) that has been created for teaching electronic commerce. In Elearn, the virtual world, the web pages and the synchronous chat among the participants are integrated into the same environment. A user is represented as an avatar who can move, make gestures with its hands and head, bump into objects, pass through them, etc. A detailed list of navigation directions is provided in order to help the user to move freely into the environment. The possibility of many users to coexist in Elearn is also supported. Collaboration and cooperation are its two components that enhance the learning effectiveness. Collaboration is supported among students and teachers with the use of synchronous chat. The chat window appears on the screen along with the virtual world and the web pages, motivating the participants to use it. Asynchronous communication is also supported, via email and discussion board.

The evaluation of a CVLE is an important and difficult task. Pedagogical issues, like conceptual learning, collaboration, constructivism and adaptability, should be taken under serious consideration. These parameters are crucial in achieving strong learning effectiveness. An evaluation table has been developed which includes all the important parameters concerning a CVLE. The evaluation is performed at four levels: 1) the pedagogical - psychological level, 2) the technical - functional level, 3) the organizational economical level, and 4) the social - cultural level. Elearn was used in an experiment supplementing traditional teaching. The students' participation was satisfactory, since they demonstrated great interest in exploring Elearn and using the synchronous chat capability. The basic pedagogical issues, like constructivism and collaboration, were fulfilled, but greater effort is needed towards the development of the lessons' content and exams. Students and teachers communicated via synchronous chat and email, as well as using the teacher's bot (an avatar that inhabits the virtual world and interacts with users). A lot of time was invested in developing and managing Elearn. Despite all the difficulties, we believe that the new methods of teaching, using CVLEs and innovative pedagogical approaches, enhance the traditional teach-

Material published as part of this journal, either on-line or in print, is copyrighted by the publisher of the Journal of Information Technology Education. Permission to make digital or paper copy of part or all of these works for personal or classroom use is granted without fee provided that the copies are not made or distributed for profit or commercial advantage AND that copies 1) bear this notice in full and 2) give the full citation on the first page. It is permissible to abstract these works so long as credit is given. To copy in all other cases or to republish or to post on a server or to redistribute to lists requires specific permission and payment of a fee. Contact Editor@ JITE.org to request redistribution permission. ing methods and improve the student participation.

Keywords: collaborative virtual learning environments, e-learning, tele-education, virtual reality.

\section{Introduction}

Virtual Learning Environments (VLEs) (Britain \& Liber, 1999) are learning management software systems that synthesize the functionality of com- 
puter-mediated communication software and on-line methods of delivering course material. Most of the systems that are currently under development are intended not simply to reproduce the classroom environment online, but also to use the technology to provide learners with new tools that facilitate learning. An Educational Virtual Environment is a system where the emphasis is mainly on the "education and collaboration" (Bouras, Psaltoulis, Psaroudis, \& Tsiatsos, 2002). Collaborative e-learning is any kind of learning process performed by more than one person that takes place mainly in a virtual environment (Michailidou, \& Economides, 2002).

The implementation of innovative pedagogical practices is a response to the social needs for educational advancement. Participants are experiencing new ways of learning and communicating with teachers by organizing the learning environment in a different way, based on several technological innovations. Additionally, one should respond to the academic, linguistic and cultural diversity of today's world, to avoid the risk of creating systems of low social, pedagogical and economic efficiency. This is the reason why the situation needs a holistic perspective of study and discussion.

\section{Tools used for Lessons Development}

Elearn is a virtual world that motivates students to participate in the educational process by exploring and playing with the lessons material, communicate with other students and teachers, and collaborate among themselves in performing several tasks. The lessons described electronic commerce issues, an attractive topic in the new information society.

Active Worlds (http://www.activeworlds.com) environment has been used for the development of the lessons, using virtual reality. This environment integrates in the same window, the virtual world, the web

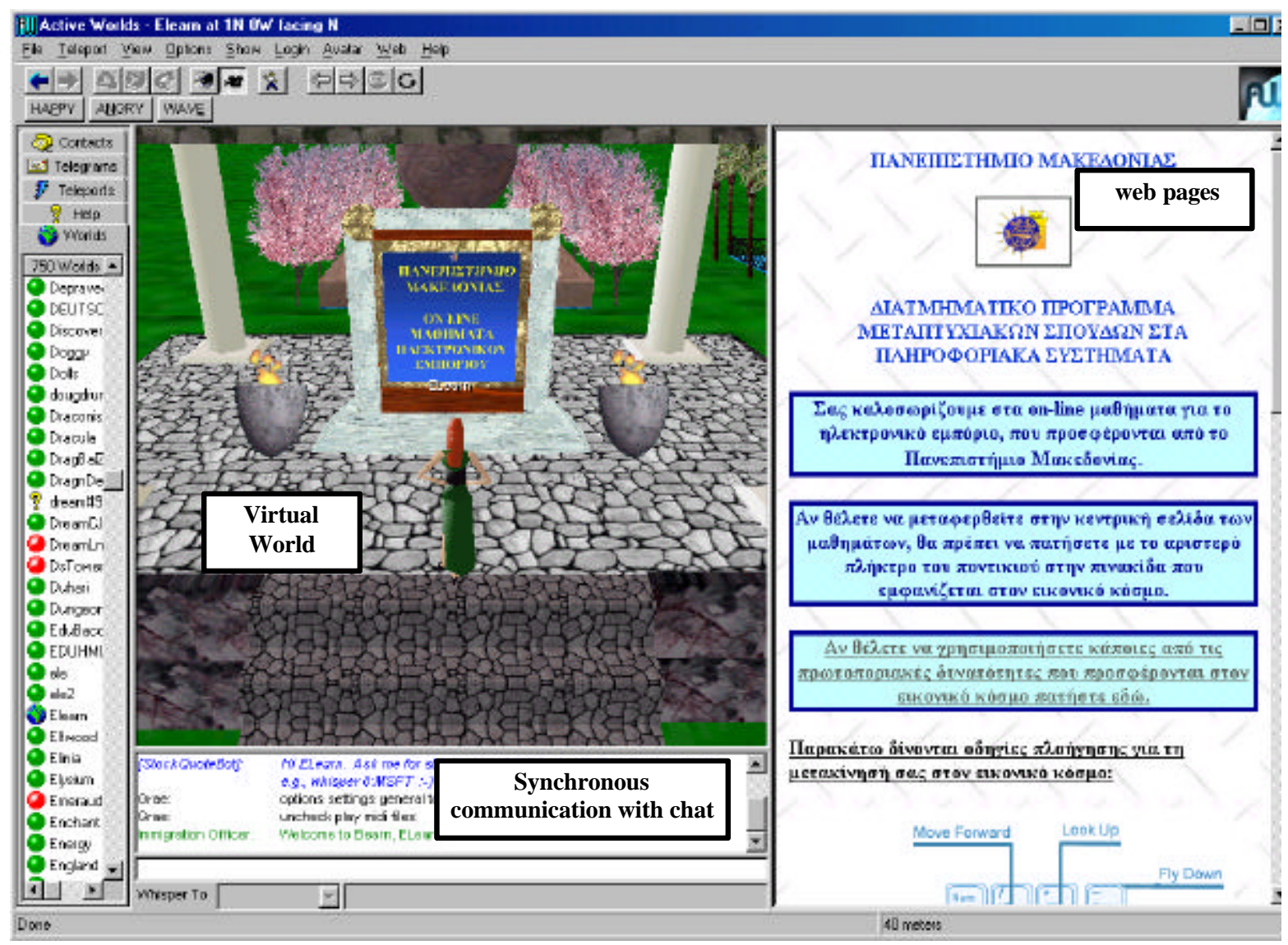

Figure 1.: The integrated environment, which was used for the lessons development. 
pages (Internet Explorer has been used for the development of the web pages) that are connected with particular incidents regarding the virtual environment and synchronous chat among the users. Synchronous chat, along with the inhabitancy of many avatars in the same virtual environment enhances collaboration. A general aspect of the environment, which has been developed, is presented in Figure 1.

Administration of the lessons has been programmed in ASP (Kauffman, \& Willis, 1999). In applications dealing with a group of users, it is necessary to develop a strong administration tool. In the first page of such a tool, the opportunity of choosing any of the offered functions must be given. In such a case the following functions must be considered: the opportunity of adding and removing users (students, teachers) and even changing some of their elements, such as their address or phone number. Only the lessons' administrator is entitled to use the above. On the other hand, a user should have the ability of searching and finding information concerning the teachers or the students.

The administration tool can be connected to a database, which has been created with an SQL Server (Specifically, an NT Server - SQL Server 7.0 with IIS4.0 has been used) through the ODBC (Open DataBase Connectivity) environment. A database has been created, with two basic tables, one for the students and one for the teachers. Both students' and teachers' tables consist of the following fields: Lastname,

Firstname, Age, Address, Tel (for the telephone), Email and Comments (for information concerning their previous education, their interests, etc.).

The web pages that are integrated in the Active Worlds environment have been created using Microsoft Front Page 2000, an environment capable of easily creating, updating and manipulating web pages. There has been an effort to integrate some necessary functions and characteristics, concerning the development of the virtual environment for the electronic commerce lessons, such as the opportunity of enrolling, searching for information, getting help, and so on.

The first page, having the role of a starter page, includes the following:

- Lesson map

- Search

- Information

- Online enrollment

- Administration

- Communication

- Online lessons of Electronic Commerce, which is the main page, concerning the lessons' development.

When the user chooses any of the above, the corresponding page appears and the navigation can lead to another or the starter page again.

- The Lesson Map choice consists of the contents of the chapters that have been developed with educational material on electronic commerce.

- The Search choice concerns the searching for information written in the lesson pages.

- The Information choice includes elements of general interest about the lessons.

- The Online enrollment choice, gives a student the ability to enroll in the lessons and a teacher to join the teachers' team, with the objective of helping in the lessons construction. The students or the teachers fill all the necessary information in the appropriate form.

- The Administration choice gives the ability of administering the lessons to the administrator. A password is necessary to add, delete and change information concerning students and teachers. Any user can search for student and teacher information. 
- The Communication choice offers to any user the ability to communicate with the administrator by sending email and asking specific questions or making certain remarks.

- The Online lessons of Electronic Commerce choice leads to the central page of the lessons. From this page, the learner can choose any of the following choices:

Introduction includes general information about electronic commerce. Navigation is easy enough, with the use of appropriate links at the beginning of the page, leading to the corresponding paragraphs. This appears to other pages too.

Contents includes the contents of the lessons.

Chapter 1 concerns the first chapter of the lessons. The user can proceed to some other paragraph of this chapter by clicking on any of the links at the beginning of the page, or on the navigation arrows that appear at the end of the page. This chapter consists of four paragraphs with text, images and navigation links. The contents include information about the World Wide Web, definitions of electronic commerce, the necessity and the advantages and disadvantages of its usage.

Chapter 2 concerns the second chapter of the lessons. It also consists of four paragraphs with text, images, tables and navigation links. Additionally, in the fourth paragraph, two videos are included as examples of two online electronic stores. The student can watch the development of these stores, make remarks and trace the interesting spots. The contents include information about the stages someone should follow in order to "build" an electronic store. Specifically the paragraphs refer to the market research that should be done before the construction of an e-store, the strategic planning which precedes, the right presentation in the World Wide Web and the final stage of actual making the online store.

Glossary consists of some basic terms, in alphabetical order, concerning the electronic commerce lessons.

Help includes information on how the user can get help, through email to either the administrator or any of the teachers or students. Additionally, some sites that give information about Frequently Asked Questions (FAQ) on electronic commerce are included.

Exercises. In order to make the application more educational, two tests are included, corresponding to the first and second chapter of the lessons. These tests consist of exercises, where the student can type the answer to the appropriate orthogonal frame and also of multiple-choice questions, where the student must choose the right answer from a group of choices. Once a student completes a test, he can click ACCEPTANCE and a new page will appear. From there, the answers can be checked and corrected, if necessary, by returning to the exercise form.

Library includes sites concerning electronic commerce in a structured way so the users can learn more according to their interests.

Discussion Board is a tool that can enhance collaborative learning. It can be used for creating discussions among interested users.

Virtual Chat also enhances collaborative learning. It can be used for synchronous chat between the participants. It also supports online discussions in the virtual classroom or even sessions in certain hours where students can ask their questions and teachers answer them. There might be a guest speaker or some expert's presentation in a certain theme of interest.

For the integration of all these functions, the Active Worlds environment has been used (http://www.activeworlds.com, http://www.activeworlds.com/tech/index.asp ). The Active Worlds environment helps the user to create a virtual world and visit a number of other available worlds. Active Worlds organization produces software that allows interactivity between users in a three dimensional virtual envi- 
ronment, through the World Wide Web. A virtual world is a place that can be inhabited by many users at the same time. The users can communicate with each other in a way that can resemble reality as their avatars appear, move and speak in the virtual world. The objects that have been placed in a virtual environment are visible to anyone who visits it. In other words, a shared virtual world uses the Active World browser in order to achieve collaboration and communication between the users. One virtual world might differ significantly from another, but they all appear in a common communication environment offered by the browser.

Any user that has downloaded the Active Worlds browser, (it is offered free in http://activeworlds.com), can visit any of the virtual worlds that appear at the main window or create his own world as a tourist or citizen. Tourists have restricted rights and can "build" in particular worlds that are "open for building." People who become a citizen have access to the following rights:

- to maintain a unique name for exclusive usage,

- to build their own possessions,

- to send telegrams (brief messages) to other citizens,

- to send files to other citizens,

- to trace and "visit" other citizens wherever they are (even in another virtual world),

- to maintain a contact list,

- to choose from a wide variety of avatars that are available to each world visited.

\section{Hardware Requirements}

In order to use Active Worlds browser, version 3.1, the following must coexist:

a) An active connection to the Internet. If a modem is in use, then a minimum rate of $56 \mathrm{Kbps}$ is proposed for better results.

b) A Pentium microprocessor of 32MB RAM at least is needed. If a 64MB RAM or larger is in use the performance improves greatly. A Direct 3D compatible video card with at least 4MB RAM and 16 bits high color is required.

c) An installation of Active Worlds software. The initial installation demands less than 5MB on hard disk, but as individuals "travel" in various virtual worlds, the objects that coincide with them are stored on the hard disk and as a result the same virtual world will be loaded considerably faster the next time the users wishes. This demands a significant amount of additional space on hard disk. At least 100MB free space on hard disk is proposed for problem-free functioning.

d) The operating system that is required for version 3.1 is Windows 98, 2000, with DirectX, version 7.0 (or later).

e) A 16-bit (at least) color graphic card must be used.

The owner of a virtual world must retain a Windows 9x/Me/NT/2000 or Linux or a Sun Solaris work station. A Windows NT/2000 or UNIX operating system is proposed. A dedicated connection to the Internet is also proposed. It is possible for someone to have her own virtual world on her PC at home, but in that case the world will be accessible only if the computer is connected to the Internet. For the world to be accessible 24 hours a day, the owner must either be connected 24 hours a day to the Internet or pay a certain amount to host her world on another server. It is possible for someone to host more than one world at the same computer. The number of the worlds depends on the capabilities of that computer. The requirements that are presented below do not include the disk space and the bandwidth that are required for the 
objects in the virtual world. The objects for a certain world could be at any site on the web. It is not necessary to be placed at the same machine where the Active Worlds Server is hosted. The disk space and the bandwidth that are required depend on the number of objects and also on their artistic outfit.

Active Worlds Server has been designed in such a way that less RAM memory, CPU capabilities and disk space will be occupied. In a typical computer with Windows 9x and 16MB RAM only one virtual world can be supported. Under Windows NT/2000 or UNIX, especially when other applications are used concurrently, at least $32 \mathrm{MB}$ RAM is proposed. Hosting a typical personal world should require less than 5 Mbytes of disk space. Larger commercial worlds and especially worlds that are open for building demand at least 20MB hard disk space. With respect to CPU capabilities, even a 486 processor would be enough. For example, for an Active Worlds Server with a world where 100 users coexist, less than $10 \%$ of a 200MHz Pentium would be satisfactory.

The bandwidth that is necessary for each visitor to a virtual world varies significantly. The demands rise when the user visits the virtual world for the first time. Then, the user's browser occupies the larger available bandwidth for a brief time period due to the massive amount of information needed for the objects to appear on screen. If the user wishes to visit the same world, the demands are going to be substantially less, as the information acquired at the first time has been stored at the hard disk. The required bandwidth can be approximately calculated by assuming an average of about 150 bytes per second for one user. Table 1 gives some information concerning the maximum number of users and the connection type. If someone hosts more than one world, the maximum numbers must be adjusted accordingly.

\begin{tabular}{|l|r|}
\hline Connection Type & \multicolumn{2}{|c|}{$\begin{array}{c}\text { Maximum number } \\
\text { of users }\end{array}$} \\
\hline 56K Modem & 20 \\
\hline DSL or cable & 100 \\
\hline T1 & 1000 \\
\hline
\end{tabular}

\section{Version 3.1 of the Active World Server supports:}

Table 1: The demands on the bandwidth with respect to the number of users.

- Multiple Worlds: one world server can host any number of worlds, although with previous versions one world server was required for one world.

- Administration: the world server offers the opportunity for administering the virtual worlds. The administration program can inspect the world servers that can "run" either at the same Windows machine or at remote Windows or UNIX units. World's server administration is an easy task and the icon that is spotted at the start line on the desktop may be used.

Figure 2 shows the administration window of the Active Worlds Server. Once the administration tool is downloaded, it may control any number of worlds that "run" at any number of servers. The tool is connected and controls one server only at a particular time instant, but one can easily select another one using the Server menu. The administration tool environment permits certain tasks, such as adding a world, changing a world or deleting a world.

After the license that permitted its usage had been acquired from the Active Worlds company (www.activeworlds.com), the virtual world that supports the electronic commerce lessons was created. The virtual world was named Elearn and its characteristics are reported in Table 2.

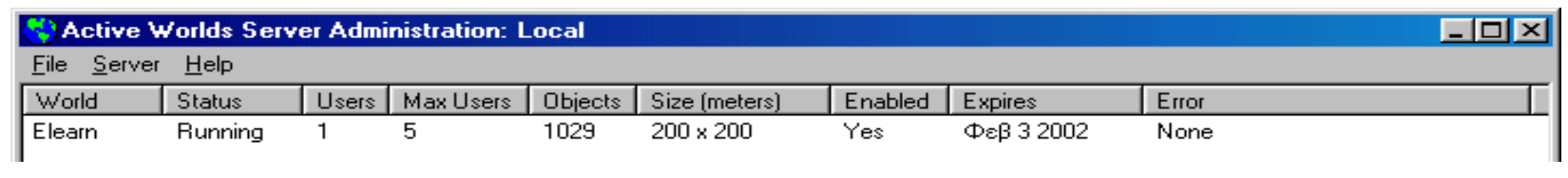

Figure 2: The Active Worlds Server Administration tool. 


\begin{tabular}{|c|c|c|c|c|c|c|c|}
\hline \multicolumn{4}{|c|}{ Server's characteristics } & \multicolumn{4}{c|}{ Charge amount } \\
\hline $\begin{array}{c}\text { World } \\
\text { Class }\end{array}$ & World size & $\begin{array}{c}\text { Maximum } \\
\text { coordi- } \\
\text { nates }\end{array}$ & $\begin{array}{c}\text { Number of } \\
\text { free citi- } \\
\text { zens }\end{array}$ & $\begin{array}{c}\text { 5 Simultane- } \\
\text { ous Users }\end{array}$ & $\begin{array}{c}\text { 10 Simulta- } \\
\text { neous Users }\end{array}$ & $\begin{array}{c}\text { 15 Simulta- } \\
\text { neous Users }\end{array}$ & $\begin{array}{c}\text { 20 Simul- } \\
\text { taneous } \\
\text { Users }\end{array}$ \\
\hline P-10 & $\begin{array}{c}40,000 \mathrm{sq} . \\
\text { meter }\end{array}$ & $10 \mathrm{~N}, \mathrm{~S}, \mathrm{E}, \mathrm{W}$ & 1 & $\$ 10$ & $\$ 60$ & $\$ 110$ & $\$ 160$ \\
\hline
\end{tabular}

Table 2: The characteristics of the virtual world.

For the administration of the virtual world, the administration tool may be used (Figure 2). From this figure it is obvious that the name of the world is Elearn, is occupied by one user at this moment and it can support a maximum of five users simultaneously. With the acquisition of the virtual world a citizen is supported, who can also be the world's administrator. A name and a password are given to this citizen, so he can attain the rights of the citizen - administrator. He can give rights regarding which users will have building rights, who will have rejection rights (it is the right to reject a user who annoys other users, for a certain time period) or who can be a public speaker (the caretaker of a world may occasionally designate certain citizens to be Public Speakers. Public Speakers are citizens whose chat messages are transmitted to all users with in a given area).

\section{Elearn: A Virtual World for Teaching Electronic Commerce}

Figure 3 presents a map of the virtual world - school.

There are six spaces to the virtual world:

- The reception room

- The selection room

- The lessons room

- The library

- The lecture room

- The electronic store

The map on Figure 3 refers to the position of each room at the virtual school, according to the north, south, east and west coordinates and to the direction of the avatar, the first time he/she visits the particular room. Once the Active Worlds environment is entered, the virtual world named Elearn may be chosen from the

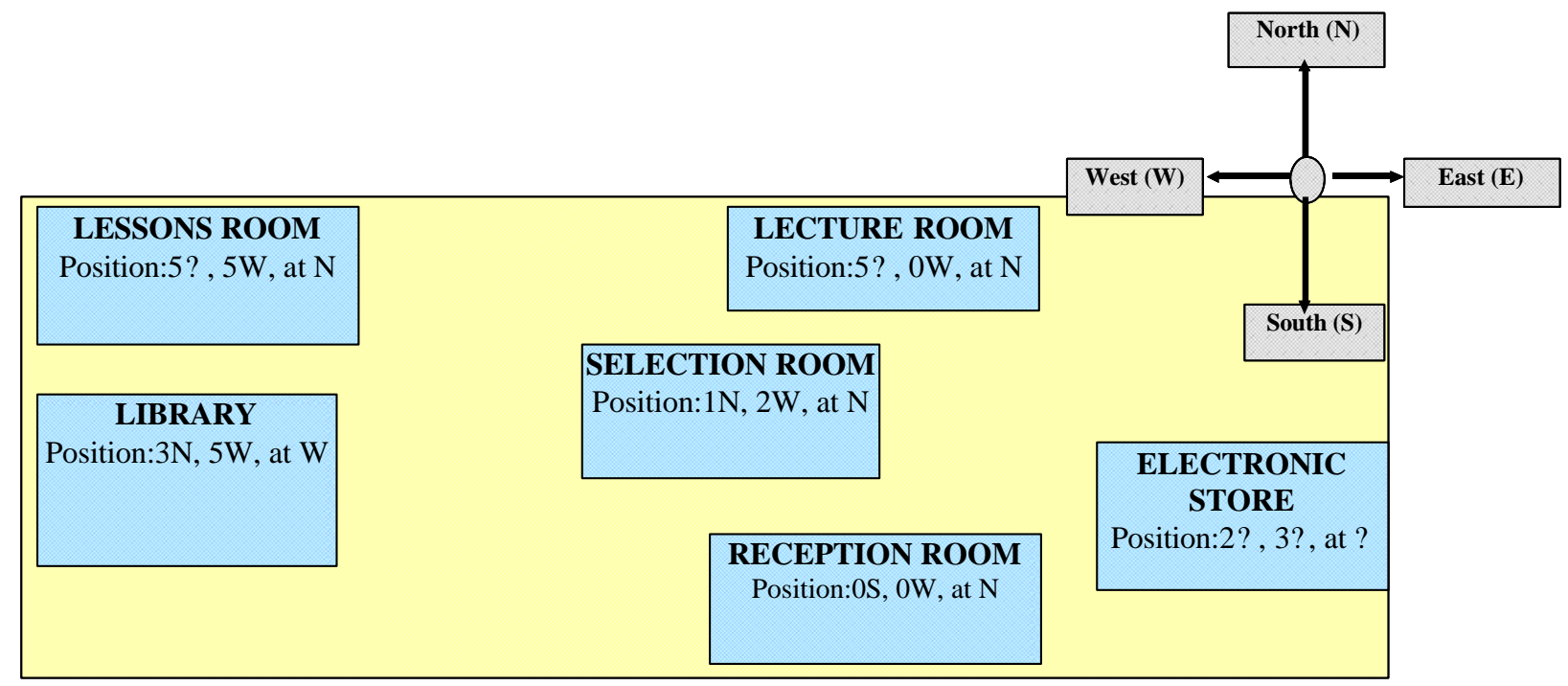

Figure 3: A map of the virtual school. 
list of virtual worlds, which is located at the left side of the screen. In the following paragraphs, a brief description of all the parts of the virtual school is given.

- The reception room contains an ancient temple with a sign placed at the center, which is welcoming the user. Additionally, at the chat window, the following message appears, "WELCOME TO THE WORLD OF ECOMMERCE!" and a corresponding sound is detected. The screen is partitioned into the virtual world window, the window where the web pages that are connected to the virtual world appear, and the chat window, where the users can chat synchronously (Figure 1). The reception room is connected to a web page that includes navigation directions to the virtual world, using the keyboard or the mouse. The map of the virtual school is also included at that page. The user is informed that if she wishes to be transferred to the main room of the lessons, she should press with the left mouse button at the sign that appears at the virtual world.

- The selection room is connected with a web page that is also the main page of the lessons and includes the following choices: Lessons Map, Search, Information, Online Enrollment, Lessons Administration, Communication and Online lessons of Electronic Commerce, which is the central page that refers to the development of the lessons. Each of the previous choices corresponds to an object at the selection room. If someone presses with the left mouse button on an object, a corresponding web page will appear. For example, if the object with the sign "ON LINE ENROLLMENT" is pressed, a web page with an enrollment form will appear at the right side of the screen.

- Lessons room includes objects with signs, each one of which is connected to a web page that contains information according to the specific topic of interest. The topics that are included are the following: Introduction, Contents, Chapter 1, Chapter 2, Glossary, Help, Exercises, Library, Discussion Board, and Virtual Chat. If the "Chapter 1" or "Chapter 2" sign is pressed, the user is transferred to the Lecture Room. If the "Library" sign is pressed the user will have the opportunity of visiting the school's library. Additionally, in certain spots of the virtual world, a mailbox is spotted. The user may use this box in order to send a message to the lessons' administrator.

- Library includes sections filled with books. Each object that contains books is divided into three sections. In the first section, a sign is placed that informs the user for the contents of the next two sections. (Figure 4). If the user left clicks on a section, he will be able to inspect the information that corresponds to that particular choice, at the web page window.

- Lecture room. The basic objects of the lecture room are the signs, the computer desks and the projection board. Every sign contains a paragraph title, from the first or the second chapter, concerning electronic commerce. If the user presses with the left mouse button on a sign, a web page concerning the correspondent paragraph will appear. If the user's avatar collides with a sign, a narration about the subject will begin. Apart from the signs corresponding to the paragraphs, there is one additional sign that refers to an example of an electronic store. If the user presses on that sign, she will be transferred to a virtual electronic store, which functions as an example and covers the objective of understanding the way of eshopping, the advantages and disadvantages of an online store.

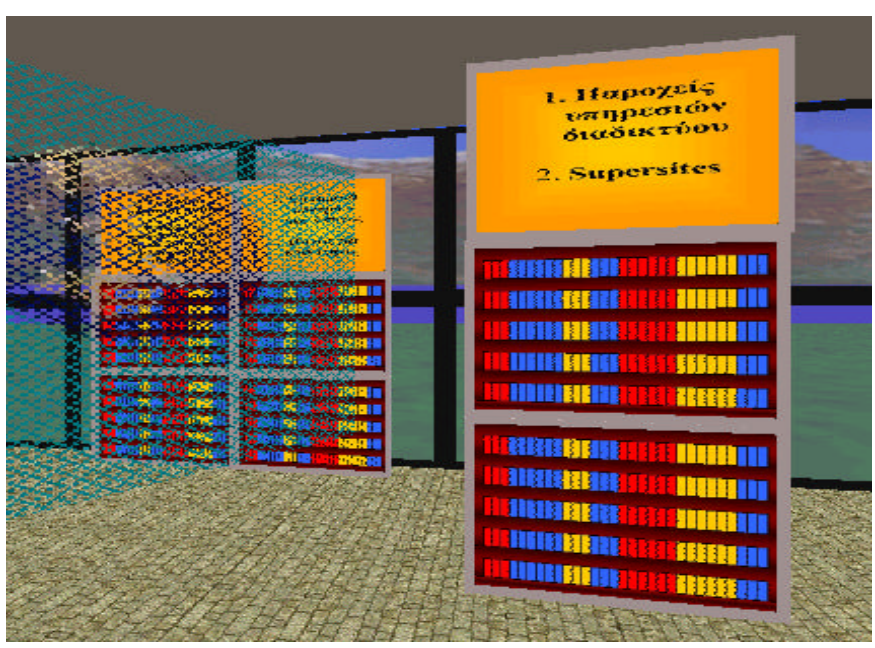

Figure 4: If the user presses on the section that refers to the Supersites, the third from above, a web page with links that are related to this term will appear. 
There are two additional signs, one for the use of the Discussion Board and the other for the Virtual Chat, which enhance collaboration.

At the left side of the lecture room, there are desks with computers. If the user approaches a computer with the mouse pointer, an explanatory sign will appear that gives information on what will happen if the computer picture is pressed. Every computer is connected to a web page and the following choices are available: Introduction, contents, library, exercises, help, glossary, teacher search and student search.

The projection board is located at the center of the room in front of the desks (Figure 5). In the lecture room, there are two lectures about electronic commerce. The projection board is used for the lecture slides change. It is possible for the lectures to be repeated at any time the administrator wishes.

- The electronic store is an example of an electronic store (Figure 6) that is located in the virtual world with the purpose of giving the students the opportunity to understand how an electronic store is constructed in the "real" world. The store that is described offers cars, motorcycles and bicycles.

Once the user is transferred into the store, the signs that welcome him appear with the message, "WELCOME TO OUR ELECTRONIC STORE." As the user keeps walking, a desk will appear in front of him. At the left side of the room some cars are located and at the right side there are motorcycles and bicycles. At the beginning, the user will see only the red color of the car model. Simultaneously, two signs appear that allow the user to see the blue and the yellow color of the same car model.

Towards the right side of the electronic store the user can see the motorcycles, while the bicycles will appear once the user left clicks on the sign with the message "PRESS HERE TO SEE THE BICYCLES." If the virtual customer wishes to make an order, he may press on the sign with the message "ARE YOU INTERESTED ON MAKING AN ORDER? PRESS HERE." This sign is located on the table at the center of the electronic store.

Once the order sign is clicked, an order form will appear at the right side of the screen, which can be filled by the future customer. From every room of the virtual world, the user can be transferred to every other room, just pressing on one of the signs that appear on appropriate places.

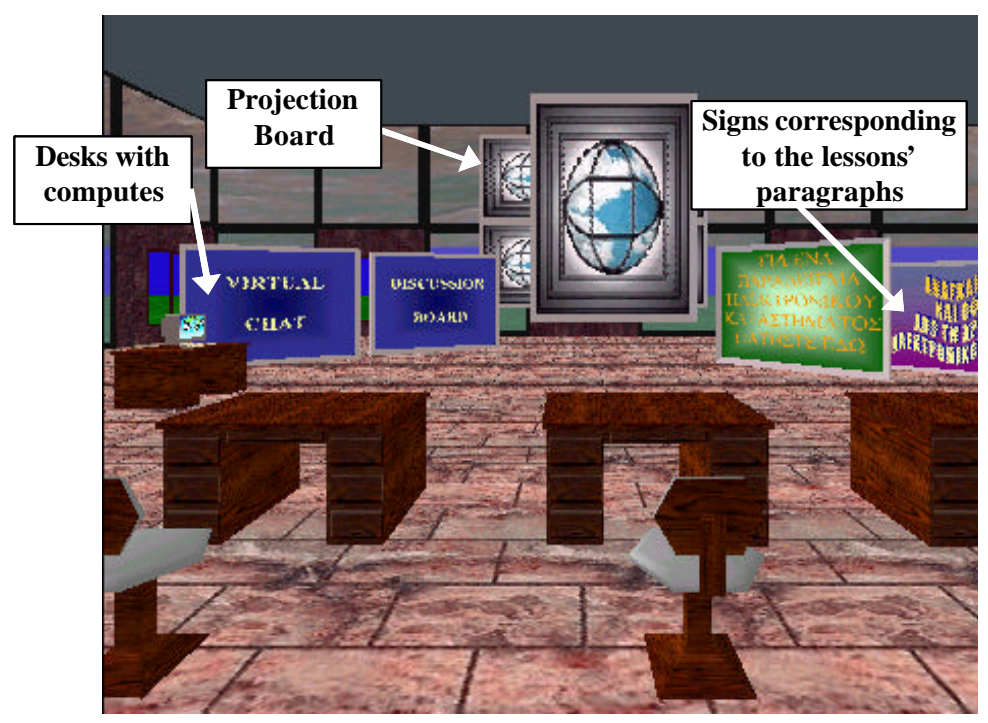

Figure 5: An aspect of the lecture room, where the basic objects are being viewed.

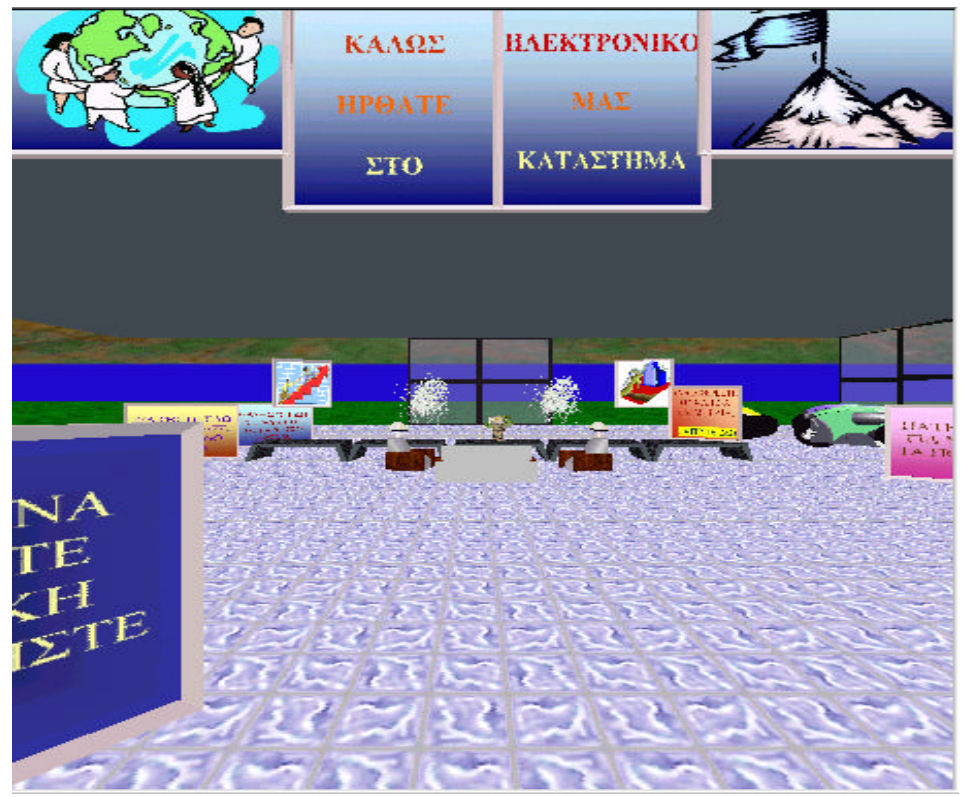

Figure 6: A view from the electronic store. 
Elearn

The Active Worlds environment offers the opportunity of using a Software Development Kit (SDK) (http://www.activeworlds.com/sdk/) that allows the programmers to develop applications. These applications can interact with the virtual world's environment created by Active Worlds software.

The most common type of application for the SDK is a bot. (A bot is typically an avatar that inhabits a virtual world and interacts with users, but it is driven by a computer program instead of a human being (citizen or tourist).) To develop an application using the Active Worlds SDK, a programmer simply writes a C program. This program is constructed in such a way that the users can interact not only with the virtual environment but with other users also. There are three (3) bots in the Elearn virtual world.

The first bot is named Teacher (Figure 7) and, as its name declares, it is built for the purpose of helping the students during their navigation of the virtual world, in order to strengthen the learning process. The teacher can appear whenever a user calls her by typing her name at the chat box. She can also disappear, if the user wishes, by typing "Leave" at the chat box.

The user can ask the teacher various questions concerning electronic commerce. The subjects about which the teacher could be asked appear at the chat box, once the user types Help. Then, the teacher responds with the following: "Ask me about the following (ecommerce, advantages, planning, aims, success, estore, question 1-5)." If the student types any of the previous words, the teacher will give him information about it.

This information appears at the chat window. Likewise, the student can see the hour if he types "Time" or get a message if he types "Thanks." The Teacher bot will be manipulated by a real teacher and therefore a discussion could be build among the teacher and some other users, based on any subject concerning the lessons and not only on the "fixed" type of discussion, using the above words.

The teacher can also examine the students by asking them questions unknown to them, apart from the ones that are already given. In order to achieve this, the administration window of the bot must be used. Additionally, a student can "whisper" (A whisper is a chat message sent directly to another user. When one whispers, the recipient is the only person who can hear what he says.) to the teacher and become recognized only by her.

The teacher is in a position to address more than one student, organize discussions and impose duties. Furthermore, as it advances in the text box, all the conversation is stored in a file, named LogChat.txt. The teacher can use this file whenever she wishes (It is assumed that the teacher is the bot's administrator.) in order to reexamine the students' answers with the purpose to grade them.

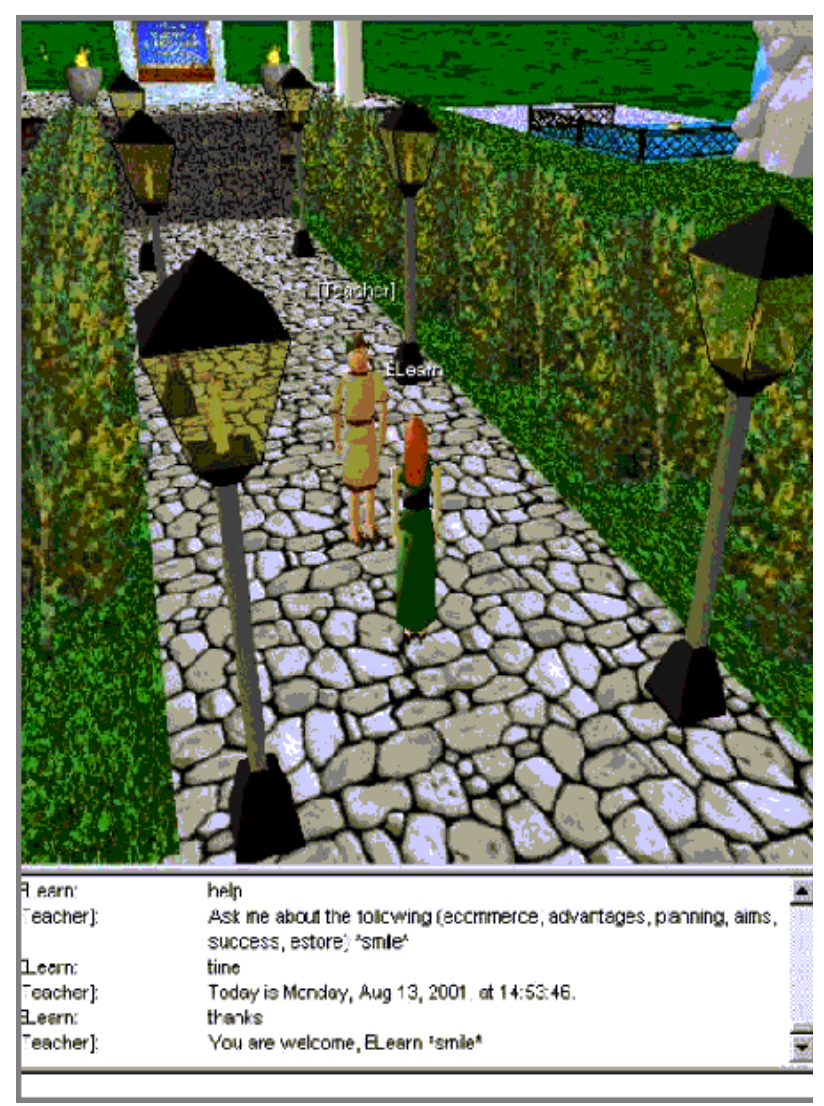

Figure 7: The teacher and the student coexist in the virtual world. 
The second bot is named Salesman (Figure 8) and its usage is to appear whenever another user (avatar) enters the electronic store. The salesman can give information concerning the products that are offered in the electronic store and advise the user of how he might fill an order form. The salesman can be used the same way as the teacher. If the word "help" is typed in the chat window, the salesman will answer the following: "Ask me about the following (goods, cars, motorcycles, bicycles, testdrive, order)."

If for example the word "cars" is entered in the chat box, information will be given concerning the cars that are offered in the store. Likewise, if the word "order" is typed, information will be given on how an order is made. As in the teacher's bot case, a discussion can be developed, with the use of the chat box.

The third bot is named Lecturer and has the capability to give lectures, in the Lecture room (Figure 9). The Lecturer can synchronize text spoken by the bot with changes in objects or .jpg images. Therefore, a virtual "slide show" can be created.

The Lecturer's bot communicates by normal chat, but its more powerful feature is the ability to whisper to the avatars that are located in the lecture room. As a result, any other avatar that exists in another room of the virtual store, for example the electronic store, will not "hear" the Lecturer. The Lecturer has the ability of presenting two lectures, with pictures that alter on the slide board and narration relative to every picture that appears.

If the user wishes to hear the narration, he must click on the picture object. As a lecture proceeds, the pictures on the slide board, which is located behind the lecturer, automatically change and the corresponding text appear in the chat box. The lectures are repeated every hour and therefore, if a student wishes to attend them again, he must enter the lecture room and simply wait.

\section{Pedagogical Issues}

Elearn is a virtual desktop educational environment, adopting a collaborative approach to courses' development, along with the support of constructivism, through the enhancement of students' experiences and the allowance of new ones. 
Jackson, \& Fagan (2000) point out that Virtual Reality (VR) in collaborative learning appears to have great potential. More research is needed before effective collaborative learning strategies can be developed. It is anticipated that these strategies will vary, depending on the kind of educational experience desired at the specific learning environment employed. Designers of hardware and software must make sure that it is easy for multiple participants to collaboratively navigate and perform tasks in VLEs.

Research on VR suggests that it could be a powerful tool for education (Micropoulos, Chalkidis, Katsikis, \& Emvalotis, 1998). Students must be encouraged to experience more, exploiting new technologies and approaching new methods of learning. In addition to immersion which has been proposed as the key point of VR for educational use, we believe that desktop virtual reality learning systems have also potential as powerful educational tools.

Some tasks can be performed only via collaboration. Educational strategies can enhance student collaborative abilities using CVLEs. The potential benefits are the ability of managing certain situations concerning the learning procedure more effectively, such as the interpretation of a task, the understanding of the goals, and the solution of a problem.

Cooperation aims at every learner's success; everyone's task is important and nobody should be in a situation of failure. Work in a team arouses mutual assistance. Regarding distance learning, collaboration is essential, because the learner belongs to a community and finds an identity. Effectiveness of collaboration depends on the composition of the team, on the learning context, on the medium for communication and on the features of the task (George, \& Leroux, 1999). In developing methods to assess the effectiveness of collaboration, group and individual performance should be considered simultaneously.

Collaboration concerns conceptual learning too. Specifically, the following questions arose:

- Can learners communicate with each other effectively?

- Can learners take advantage of the freedom of movement and technology provided by CVLEs?

- Does collaboration promote conceptual learning?

Effective communication among the students includes discussions about how to approach the learning issue, who is to do what and when, what the conceptual difficulties are, what has been learned and how ambiguities can be removed. Under the conceptual point of view, the design and development of a VR system for educational applications focuses on the cognitive, intellectual, social and emotional processes of the student (Micropoulos, Chalkidis, Katsikis, \& Kossivaki, 1997).

Generally, learners do take advantage of the possibilities given by the freedom to move in a CVLE, and also of the technology provided. Freedom in navigation and interaction is essential for a virtual environment designed to educate the users. One of the CVLE objectives is to provide such experiences that are difficult to obtain in the real world.

The basic theoretical statement of constructivism leads to the estimation that techniques like the strict planning of the didactic content or the form of interactivity in the typical educational process are inefficient. Students have to work in an environment where they can construct knowledge by themselves. Since real environments are not always available, artificial environments can be used.

Constructivism has been proposed as the best basis for building a theory of learning in virtual environments (Micropoulos, Chalkidis, Katsikis, \& Kossivaki, 1997). Although constructivism is connected with fully immersive VR systems, it is believed that its aims are fulfilled with desktop systems too. Users in desktop VR systems are not immersed in virtual worlds. Nevertheless, some basic principals are being fulfilled: learners can proceed at their own pace, interaction is required and active participation is encouraged rather than passivity. 
The issue of adaptability is also essential. The representation of information in VR can be compatible to the different learning styles of students and the different ways that people acquire information and think. CVLEs can support adaptive curriculum generation, on-demand quizzes and tutorials, interactivity in learning elements involving multimedia animations and dialogues, interaction among tutors and learners through asynchronous and synchronous communication, flexibility of time and location of learning.

\section{Learning Effectiveness Evaluation}

The evaluation of a CVLE is not a simple task (Holst, \& Holmer, 2000). Without a descriptive model of the ideal collaborative learning process, we cannot easily find indicators (either qualitative or quantitative) that will tell us whether effective learning is taking place. Neither are we in a position to assess whether a new technology adds or subtracts from this process; we should consider how to create models of learning that explain and predict the behavior of virtual learning groups supported by technology. The effectiveness of new technology should be considered at a number of different levels simultaneously.

In contrast to traditional ways of computer - supported learning, e.g., a single individual using a PC to navigate through a CD -based multimedia course, CVLEs include a number of complexities for evaluation (Pfister, Wessner, Holmer, \& Steinmetz, 1999). Additionally, on the level of evaluation criteria, the criteria themselves need to be changed and adapted according to new findings and new constrains that result from system development. Therefore, formative evaluation needs to be performed at four levels simultaneously: A) the pedagogical - psychological level, B) the technical - functional level, C) the organizational - economical level and D) the social - cultural level.

The pedagogical - psychological level includes all the criteria, referring to the learning process itself. For example, criteria such as support of different didactic methodologies, how to represent and modify knowledge, tools to define learning goals, or support for different roles (learners, trainers, tutors) need to be assessed at this level.

The technical - functional level includes criteria that refer to the proper functioning of a concrete system, e.g., criteria such as stability, required bandwidth, interface design, etc.

The organizational - economical level deals with aspects of organizational context and constraints, e.g. how efficient and cost - effective are computer - supported learning processes compared to traditional ways of training.

Finally, the social - cultural level evaluates how a system fits into the overall learning culture and how its users from a motivational and emotional point of view accept it. A model of evaluating CVLEs has been developed (Michailidou, Economides, \& Georgiadou, 2001; Georgiadou, \& Economides, 2000; Jackson, \& Fagan, 2000; Georgiadou, Economides, Michailidou, \& Mosha, 2001) based on the previous factors. Therefore, the evaluation of the virtual collaborative environment, named Elearn, is a complex task where various parameters must be taken under consideration. The Table 3 includes the evaluation criteria. A diagram with the basic evaluation axes is also presented in Figure 10.

It is obvious that the evaluation of a collaborative virtual environment is a complex and versatile task where many parameters must be taken into consideration. Furthermore, the true evaluation of software occurs after the environment is tested by the students and teachers that use it. They can grade the software and suggest ways of improvement. Furthermore, the evaluation procedure is time consuming. It is necessary for the teachers and students to develop a certain friction with the environment in order to understand its advantages and disadvantages. 


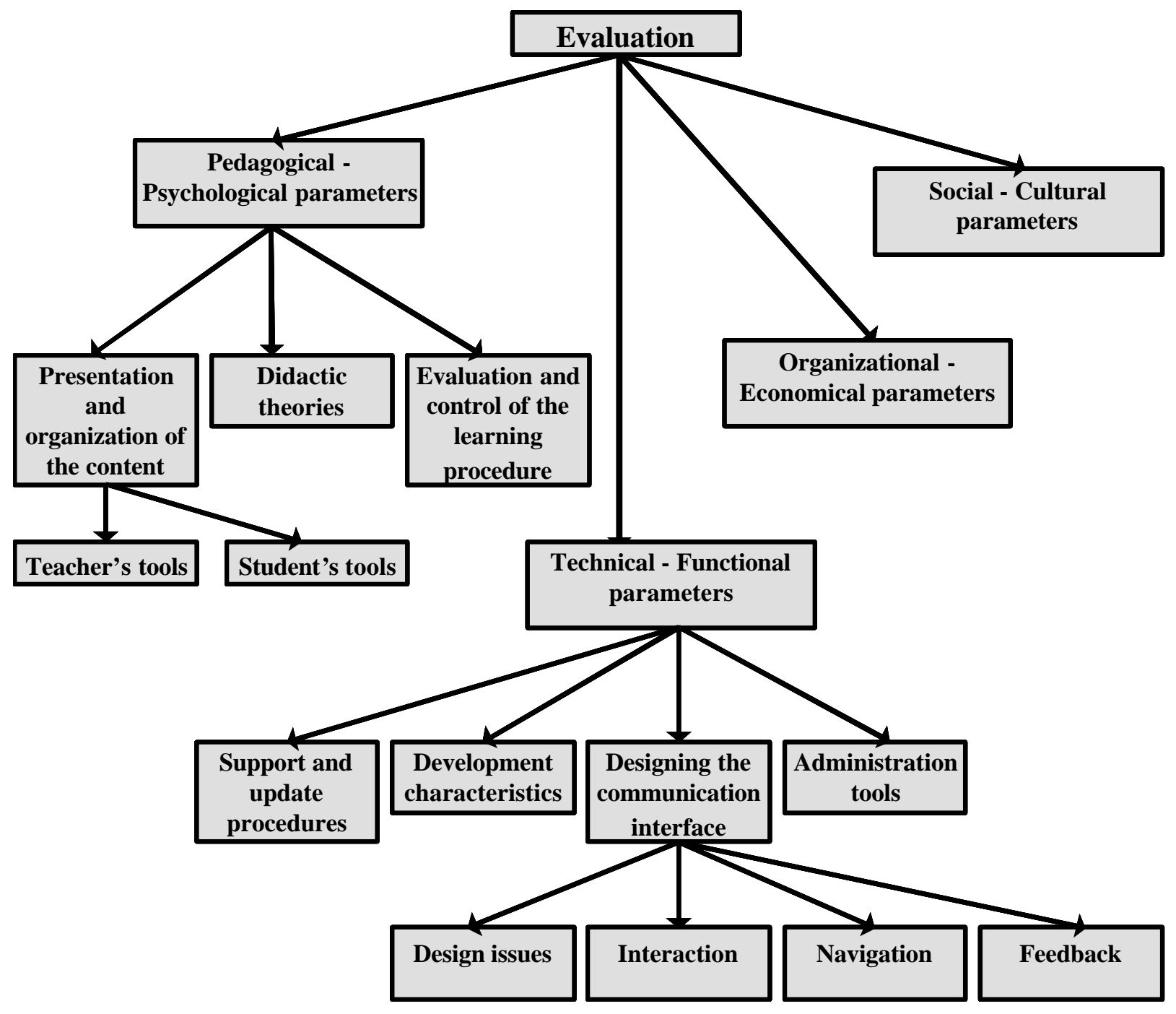

Figure 10: A diagram with the basic evaluation axes for a Collaborative Virtual Environment.

Elearn was used as an additional tool for the teaching of Electronic Commerce to undergraduate students. All the students had common theoretical background, approximately the same age (18-22) and prior computer experience, but no experience in using CVEs. A questionnaire based on Table 3 was formed and given to twenty of the students, in order to evaluate the environment. The grading included five numbers ( 1 to 5), each number corresponding to the degree of truth concerning the statement. For example, if collaborative learning is supported, then the grading will be five (perfect) or four (less than perfect), three or two if it is partially supported and one if it is not supported at all. At the third column of table 3 appears the grading of the majority of the students and in the fourth column the percentage of the students that gave this grading. The issues evaluated were only these that considered being of students' interest. 


\section{Evaluation parameters}

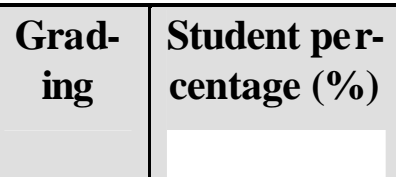

\section{\begin{tabular}{l|l} 
A. & Pedagogical - Psychological parameters
\end{tabular}}

\begin{tabular}{|l|l|}
\hline A.1. & Didactic theories \\
\hline A.1.1. & Collaborative learning is supported. \\
\hline A.1.2. & $\begin{array}{l}\text { The individuality of each student, in regard to his/hers cultural and social de- } \\
\text { velopment is taken under consideration. }\end{array}$ \\
\hline A.1.3. & $\begin{array}{l}\text { The individuality of each student, in regard to his/hers prior learning exper- } \\
\text { ence is taken under consideration. }\end{array}$ \\
\hline A.1.4. & $\begin{array}{l}\text { Collaboration among the tutors for the purpose of communication and com- } \\
\text { mon creation is supported (team building). }\end{array}$ \\
\hline A.1.5. & $\begin{array}{l}\text { Students can get help in order to be encouraged and motivated (building mot } \\
\text { vation). }\end{array}$ \\
\hline
\end{tabular}

\begin{tabular}{|l|l|r|r|}
\hline A.2. & Presentation and organization of the content & 4 & 60 \\
\hline A.2.1. & The content is valid and trustworthy. & 4 & 50 \\
\hline A.2.2. & The content, to its greater degree, agrees to the analytical curriculum. & 4 & 65 \\
\hline A.2.3. & The content corresponds to the age group in which it addresses to. & 4 & 80 \\
\hline A.2.4. & The content corresponds to the aim of learning. & &
\end{tabular}

\begin{tabular}{|c|c|c|c|}
\hline A.2.5.1. & The teacher can participate in the planning and manipulation of the lessons. & & \\
\hline A.2.5.2. & It is easy to monitor and renew the lessons. & & \\
\hline A.2.5.3. & There are instructions for the lessons' teaching. & & \\
\hline A.2.5.4. & The capability of online monitoring and grading the students exists. & & \\
\hline A.2.5.5. & $\begin{array}{l}\text { The teacher must be familiar with programming (html or other languages) and } \\
\text { generally specific knowledge in certain fields is being demanded. }\end{array}$ & & \\
\hline A.2.5.6. & Automated grading of the students is supported. & & \\
\hline A.2.5.7. & $\begin{array}{l}\text { Course monitoring is easy for the teacher (e.g. control of the information us- } \\
\text { age and the lesson's sources from one or many students). }\end{array}$ & & \\
\hline A.2.5.8. & Teachers are helped to create learning sequences. & & \\
\hline A.2.5.9. & $\begin{array}{l}\text { There are tools for exercises, quizzes, examination tests ,e.t.c. for the stu- } \\
\text { dents. }\end{array}$ & & \\
\hline$? .2 .5 .10$ & $\begin{array}{l}\text { Teachers are allowed to use tools for the purpose of common knowledge us- } \\
\text { age (e.g. databases with advice on how the lessons should carried out, exer- } \\
\text { cises, e.t.c.) }\end{array}$ & & \\
\hline A.2.6. & Student's tools & & \\
\hline A.2.6.1. & Students are allowed to use online help. & 5 & 90 \\
\hline
\end{tabular}




\begin{tabular}{|c|c|c|c|}
\hline \multicolumn{2}{|r|}{ Evaluation parameters } & \multirow{2}{*}{$\begin{array}{c}\begin{array}{c}\text { Grad- } \\
\text { ing }\end{array} \\
1\end{array}$} & \multirow{2}{*}{$\begin{array}{l}\text { Student per- } \\
\text { centage }(\%)\end{array}$} \\
\hline A.2.6.2. & Each student can use a private email account. & & \\
\hline A.2.6.3. & A bulletin board is offered. & 2 & 75 \\
\hline A.2.6.4. & A discussion list is offered. & 1 & 80 \\
\hline A.2.6.5. & $\begin{array}{l}\text { Asynchronous communication is being supported (BBS- Bulletin Board Ser- } \\
\text { vice, file exchange via Internet, newsgroups). }\end{array}$ & 5 & 90 \\
\hline A.2.6.6. & $\begin{array}{l}\text { Synchronous communication is being supported (Internet Relay Chat - IRC, } \\
\text { voice chat that permits to two or more participants to communicate with the } \\
\text { help of a microphone in real time, audio conferencing, video conferencing, } \\
\text { whiteboard - a distributed window for text or drawing-, application sharing, } \\
\text { meetings on virtual spaces). }\end{array}$ & 5 & 85 \\
\hline A.2.6.7. & $\begin{array}{l}\text { Each student has access to his/hers grading and progress, concerning the les- } \\
\text { sons. }\end{array}$ & 2 & 70 \\
\hline A.2.6.8. & A glossary is available. & 5 & 75 \\
\hline A.2.6.9. & A content tool is available. & 5 & 85 \\
\hline A.2.6.10 & Search is being supported. & 5 & 80 \\
\hline A.2.6.11 & $\begin{array}{l}\text { Study skill building is supported, e.g. effective learning, how the learning pro- } \\
\text { cedure is to proceed, tools for repeating the lessons). }\end{array}$ & 1 & 90 \\
\hline A.3. & \multicolumn{3}{|l|}{ Evaluation and control of the learning procedure } \\
\hline A.3.1. & $\begin{array}{l}\text { Each student is in a position to use the software independently, without the } \\
\text { help of the teacher or the help of a book. }\end{array}$ & 5 & 45 \\
\hline A.3.2. & The student can interact freely with the software. & 4 & 50 \\
\hline A.3.3. & The environment enhances learning on action. & 5 & 70 \\
\hline A.3.4. & Multiple-choice questions are used in lessons' development. & 5 & 75 \\
\hline A.3.5. & Right - wrong questions are used in lessons' development. & 5 & 70 \\
\hline A.3.6. & Fill in the blanks questions are used in lessons' development. & 5 & 80 \\
\hline A.3.7. & Some questions are to be answered with a short or more extended way. & 5 & 75 \\
\hline A.3.8. & There is a time constrain is some questions or answers. & 1 & 85 \\
\hline A.3.9. & Exercises that can be assigned to a group of students are concluded. & 3 & 55 \\
\hline B. & \multicolumn{3}{|l|}{ Technical - Functional parameters } \\
\hline B.1. & \multicolumn{3}{|l|}{ Development characteristics } \\
\hline B.1.1. & $\begin{array}{l}\text { Multimedia capabilities are supported (pictures, sound, video, VRML files, } \\
\text { e.t.c.) }\end{array}$ & 5 & 75 \\
\hline B.1.2. & $\begin{array}{l}\text { Application software can be used in different platforms (Windows } \\
95 / 98 / 2000 / \mathrm{NT} \text {, Macs with OS } 7.0 \text { or later). }\end{array}$ & 5 & 60 \\
\hline B.1.3. & Server software can be used in different platforms (UNIX, Windows NT). & 5 & 65 \\
\hline
\end{tabular}




\begin{tabular}{|c|c|c|c|}
\hline \multicolumn{2}{|r|}{ Evaluation parameters } & \multirow{2}{*}{$\begin{array}{c}\begin{array}{c}\text { Grad- } \\
\text { ing }\end{array} \\
1\end{array}$} & \multirow{2}{*}{$\begin{array}{c}\text { Student per- } \\
\text { centage }(\%) \\
80\end{array}$} \\
\hline B.1.4. & An interconnection with a database is supported. & & \\
\hline B.1.5. & $\begin{array}{l}\text { Software supports a browser (Microsoft Internet Explorer, or Netscape Navi- } \\
\text { gator). }\end{array}$ & 5 & 90 \\
\hline B.1.6. & There has been a prediction for disabled people. & 1 & 100 \\
\hline B.2. & \multicolumn{3}{|l|}{ Designing the communication interface } \\
\hline B.2.1. & \multicolumn{3}{|l|}{ Design issues } \\
\hline B.2.1.1. & $\begin{array}{l}\text { Screens are designed in a clear and interesting way, drawing student's atten- } \\
\text { tion. }\end{array}$ & 4 & 40 \\
\hline B.2.1.2. & Text enhances information, without making the application monotonous. & 4 & 50 \\
\hline B.2.1.3. & $\begin{array}{l}\text { Graphics and pictures are being used, without provoking student's disorienta- } \\
\text { tion. }\end{array}$ & 4 & 60 \\
\hline B.2.1.4. & The sound used enhances information. & 5 & 70 \\
\hline B.2.1.5. & The video used enhances information. & 5 & 65 \\
\hline B.2.1.6. & The user is embodied with an avatar in the virtual environment. & 5 & 90 \\
\hline B.2.1.7. & $\begin{array}{l}\text { The selection and manipulation of the objects in the virtual world can be eas- } \\
\text { ily carried out. }\end{array}$ & 4 & 40 \\
\hline B.2.1.8. & Multiple object selection is permitted. & 5 & 55 \\
\hline B.2.1.9. & The position and orientation of each object is accurately described. & 5 & 40 \\
\hline B.2.1.10 & An avatar demonstrates face, hands and body gestures. & 5 & 65 \\
\hline B.2.1.11 & $\begin{array}{l}\text { Immersion is being supported with the use of suitable devices, like the stereo- } \\
\text { scopic glasses, the sensor gloves, e.t.c.. }\end{array}$ & 1 & 100 \\
\hline B.2.1.12 & $\begin{array}{l}\text { The user has the right to change the properties of an object in the virtual } \\
\text { world. }\end{array}$ & 1 & 100 \\
\hline B.2.1.13 & $\begin{array}{l}\text { The user can change the point of view from which the objects and other users } \\
\text { are seen in the virtual environment. }\end{array}$ & 5 & 65 \\
\hline B.2.2. & Interaction & & \\
\hline B.2.2.1. & $\begin{array}{l}\text { The interaction with the system is done with an easy way, complying with the } \\
\text { learning team to which the software is addressed. }\end{array}$ & 4 & 45 \\
\hline B.2.2.2. & Student to student and teacher to student interaction is being supported. & 4 & 80 \\
\hline B.2.2.3. & $\begin{array}{l}\text { Interaction can occur in the optical or acoustic field, through body move- } \\
\text { ments, or even with a combination of the above. }\end{array}$ & 3 & 70 \\
\hline B.2.3. & Navigation & & \\
\hline B.2.3.1. & Navigation is carried out easily. & 4 & 60 \\
\hline B.2.3.2. & $\begin{array}{l}\text { Multiple types of navigation are supported (e.g. for beginners, advanced, } \\
\text { e.t.c.). }\end{array}$ & 1 & 85 \\
\hline
\end{tabular}




\begin{tabular}{|c|c|c|c|}
\hline \multicolumn{2}{|r|}{ Evaluation parameters } & \multirow{2}{*}{$\begin{array}{c}\begin{array}{c}\text { Grad- } \\
\text { ing }\end{array} \\
5\end{array}$} & \multirow{2}{*}{$\begin{array}{l}\text { Student per- } \\
\text { centage }(\%)\end{array}$} \\
\hline B.2.3.3. & Lessons include a content table. & & \\
\hline B.2.3.4. & $\begin{array}{l}\text { The basic navigation buttons are included in each page (e.g. next, previous } \\
\text { page, return to the first page). }\end{array}$ & 5 & 90 \\
\hline B.2.3.5. & A help button is included. & 5 & 100 \\
\hline B.2.3.6. & A search button is included. & 5 & 100 \\
\hline B.2.3.7. & A navigation map is included, shown all the domains of the virtual world. & 5 & 90 \\
\hline B.2.3.8. & A pedagogical agent is included with the purpose of guide the students. & 1 & 100 \\
\hline B.2.3.9. & $\begin{array}{l}\text { There has not been a report of tiredness and seasickness after long exposure } \\
\text { to the environment. }\end{array}$ & 3 & 45 \\
\hline B.2.4. & \multicolumn{3}{|l|}{ Feedback } \\
\hline B.2.4.1. & $\begin{array}{l}\text { Student's answers in various tests or questions can provoke a reaction by the } \\
\text { environment. }\end{array}$ & 2 & 75 \\
\hline B.2.4.2. & There is a feedback, concerning the software use. & 2 & 60 \\
\hline B.2.4.3. & Feedback is supported with the use of sounds, lighting, e.t.c.. & 2 & 45 \\
\hline B.2.4.4. & $\begin{array}{l}\text { Avatars can demonstrate special movements, corresponding to specific ways } \\
\text { of behavior, like applause after a right answer, e.t.c.. }\end{array}$ & 4 & 80 \\
\hline B.3. & \multicolumn{3}{|l|}{ Support and update procedures } \\
\hline B.3.1. & $\begin{array}{l}\text { An instruction book is included, concerning software use for the teachers and } \\
\text { students. }\end{array}$ & & \\
\hline B.3.2. & Technical support is available. & & \\
\hline B.3.3. & $\begin{array}{l}\text { The user has access to libraries, bibliographic sources or databases, with the } \\
\text { purpose of select information concerning the lessons. }\end{array}$ & & \\
\hline B.3.4. & Software is being updated often as well as the site is maintained. & & \\
\hline B.3.5. & The security is adequate, for file exchange, email, grading, e.t.c.. & & \\
\hline B.3.6. & $\begin{array}{l}\text { Mirror sites are included, offering an alternative solution when problems } \propto \text { - } \\
\text { cur. }\end{array}$ & & \\
\hline B.3.7. & There are instructions concerning software installation. & & \\
\hline B.4. & \multicolumn{3}{|l|}{ Administration tools } \\
\hline B.4.1. & Crash recovery tools are included. & & \\
\hline B.4.2. & Backup procedures are supported. & & \\
\hline B.4.3. & There are tools that prohibit unauthorized access to the server. & & \\
\hline B.4.4. & Online enrolling and payments are supported. & & \\
\hline B.4.5. & There is the possibility for a guest to use an account (guest account creation). & & \\
\hline B.4.6. & $\begin{array}{l}\text { There is an administration tool for the lessons (creation of new accounts, de- } \\
\text { letion or updating elements about students or teachers). }\end{array}$ & & \\
\hline
\end{tabular}




\begin{tabular}{|c|c|c|c|}
\hline \multicolumn{2}{|r|}{ Evaluation parameters } & \multirow{2}{*}{$\begin{array}{l}\text { Grad- } \\
\text { ing }\end{array}$} & \multirow{2}{*}{$\begin{array}{l}\text { Student per- } \\
\text { centage }(\%)\end{array}$} \\
\hline B.4.7. & $\begin{array}{l}\text { The administrator has the right to determine access rights for teachers and } \\
\text { students. }\end{array}$ & & \\
\hline B.4.8. & Remote access is being supported. & & \\
\hline C. & \multicolumn{3}{|l|}{ Organizational - Economical parameters } \\
\hline C.1. & $\begin{array}{l}\text { The provider, who has developed the software, can host the lessons to a } \\
\text { server. }\end{array}$ & & \\
\hline C.2. & The provider uses advertisement policy in order to support the lessons. & & \\
\hline C.3. & The provider is the owner of lessons' content. & & \\
\hline C. 4 . & Pricing policy is based on the number of the students. & & \\
\hline C.5. & Pricing depends on the time that a student is using the lessons. & & \\
\hline C.6. & Technical support, if exists, is being charged separately. & & \\
\hline D. & \multicolumn{3}{|l|}{ Social - Cultural parameters } \\
\hline D.1. & $\begin{array}{l}\text { Team communication is supported, taking under consideration possible differ- } \\
\text { ences in religion or in cultural development. }\end{array}$ & 1 & 50 \\
\hline D.2. & The environment supports multilingual capabilities. & 1 & 100 \\
\hline D.3. & Sex differences are taken under consideration. & 1 & 80 \\
\hline D.4. & Age differences are taken under consideration & 1 & 85 \\
\hline
\end{tabular}

Table 3: An evaluation framework of the Elearn environment.

Although the traditional way of learning has the main advantage of physical and immediate, face to face contact, students demonstrated significant interest in exploring and learn through the use of a CVLE. Such an environment provides the capability of using the network, information and communication technology, in order to intensify the educational procedure. Still, the majority of the students stated that they feel more comfortable if a combination of both traditional and neoteric method of teaching is to be used. In particular, they propose that an innovative educational environment should only be used when it truly improves learning and when practical difficulties arise, like in the case of distance learning.

Collaborative learning is supported with the inhabitancy of many avatars at the same virtual world and the use of synchronous chat. Discussion board and virtual chat were also used. Students demonstrated an urge to use the synchronous chat capability and especially enjoyed the fact that they could impersonate themselves with the use of an avatar. A team project had been assigned, (each team consisted of 2 or 3 students) and a specific task was given. The results were satisfactory, although some students found peculiar the situation in which they had to move around in the virtual world, in order for example to get to the library. They also stated that is was time consuming that they had to send emails to find a common time schedule in order to inhabit the virtual world at the same time with their team mates. Nevertheless, collaboration with the use of a distributed networked virtual environment has been proved quite useful at distance learning, since a student is allowed to participate, practically from everywhere, as long as he/she possesses the adequate equipment and an Internet connection.

With regards to adaptability, students stated that they felt autonomous enough to explore and learn at their own pace. A drawback concerning adaptive learning was that the content of the lessons was common for 
everyone and there was no prediction concerning prior learning experience in the subject. Therefore, a further development of the content is necessary, in order to expand the field of analysis. Still, each student can use the library to find the matter that particularly is of interest to him and teachers can prepare and use tests and questions at different levels of difficulty. Additionally, further work has to be done in order to encounter issues like age, sex or cultural differences. The language used was Greek, since the lessons were addressed to Greek students, but it is simple to develop it on a different language, which will widen the prospects of the software usage, especially for distance learning purposes.

As for teacher tools, teachers are free to participate in the lessons' development, give exercises or grade students online. It is essential for the teacher to have some basic knowledge of the tools that must be used in order to fully attain the capabilities of the environment, to make a new test or to communicate with another teacher or student. Course monitoring is simple, since text files with the conversation of a teacher student are created when the teacher is impersonated with the form of a bot. Consequently, all the student's answers can be analyzed and graded at a different time, whenever the teacher decides to do so. The teacher can set a time schedule regarding the time that he/she is going to be online, for the purpose to communicate synchronously with the students.

Students can get help (the bots are essential) about the lessons. A glossary and a content table are available. Searching is also included so that someone can find information related to the theme of his interest. Each student is able to email at any time to his/her instructor. Asynchronous communication is supported with the use of email and file exchange via Internet. Newsgroups are not included. Participants can use the chat window, for synchronous communication. Audio conferencing and video conferencing are not included. More attention should be given at monitoring the students' progress.

The usage and navigation in the environment is easy and pleasant, through user's interface. The students felt free to navigate in the environment, after a short period of time, without getting any help from the instructors. They can interact with the environment under certain constraints- for example, they cannot change the properties of an object, or build anywhere in the virtual world-, but they can move freely, pass through objects and visit any virtual room. Common ways of interactivity with the environment were also been used (e.g. signs), with the purpose to provoke the students to explore and learn. The user can be personalized with an avatar, facial and body gestures are supported, but immersion is not supported. The majority of the students felt that the use of the virtual environment enhanced learning on action. They stated that the use of the virtual store was a "constructive experience." The lessons' development contained tests with a lot of types of questions (multiple choice, right - wrong, etc.) and also exercises assigned to a group of students. Students found interesting the group work suggested to them in the lecture room. There are no interactive tests included at this time. Feedback is supported, but it is relatively weak, since it exists only in the form of applause or short text messages.

Various multimedia elements are supported at the lessons' development, like sound and video. The software can be used in different platforms and supports Microsoft Internet Explorer. The server can host more than one virtual world, so future expansion is possible. The possibility of connecting to a database wasn't studied and there has been no prediction for disabled people for the time being.

Regarding support and update procedures, students and teachers can get help concerning the software installation and usage and also the technical requirements. The procedure of updating the content and the security problem need more work. There are no mirror sites. It is possible for the lessons' administrator to retain backup files of the virtual world. Online enrolling is possible and an administration tool has been developed. The ability of adding, changing and deleting elements relating to students or teachers is entitled only to the administrator. There wasn't any study made on advertisement and pricing policy.

In conclusion, we believe that CVEs can assist the educational community to improve the educational process. The integration of information and communication technologies offers unlimited capabilities to educational applications and will become not only a challenge but also a necessity for the future. 


\section{Future Work}

The current research and commercial interest in developing CVEs that support rich social interaction in densely populated virtual worlds is an ambitious goal, one that requires addressing a variety of technical challenges (Benford, Greenhelgh, Rodden, \& Pycock, 2001).

Based on future growth, the conjunction of virtual environments with databases that are continuously enriched with new elements in order to be synchronous is an interest aspect (Davison, \& Vreede, 2001: Nunes, Dihl, Fraga, Woszezenki, Oliveira, Francisco, Machado, Nogueira, \& Notargiacomo, 2002). Another capability of great interest is teleimmersion, integrating CVE and audio, video conferencing and other demanding technologies for computer power and network bandwidth.

Also, the addition of smart behavior to the system with the usage of intelligent agents is something worth of studying. The combination of Artificial Intelligence and 3D environment technologies with innovative interface design offers great opportunities for efficient learning. Pedagogical agents are of great importance and can be used in CVEs, as they are represented with a character (avatar), or a specific object (for example, a book). The software agent technology and learning objects technology will revolutionize online teaching and learning. The agent - based software paradigm is partially suitable for developing distributed systems as it enhances speed, reliability and flexibility in a learning environment.

The ongoing research involving VLEs is worthwhile, considering that the networking of multi - participant CVEs appears to represent a significant trend for future applications (Redfern, \& Naughton, 2002).

\section{References}

Benford, S., Greenhelgh, C., Rodden, T., \& Pycock, J. (2001). Collaborative virtual environments. Communications of the ACM, Volume 44, Issue 7, pp 79-85. ISSN: 001-0782.

Bouras, C., Psaltoulis, D., Psaroudis, C., \& Tsiatsos, T. (2002). An educational community using collaborative virtual environments. ICWL, LNCS 2436, pp. 180-191. Springer.

Britain, S., \& Liber, O. (1999). A framework for pedagogical evaluation of virtual learning environments. University of Wales - Bangor Retreived May 2003, from http://www.jtap.ac.uk/reports/htm/jtap-041.html

Davison, R., \& Vreede, G.J. (2001). Global applications of collaborative technology: Introduction. Communications of the $A C M$, Vol. 44, Issue 12, pp. 68-70, ISSN: 0001-0782.

George, S., \& Leroux, P. (1999). Computer - supported project pedagogy in a distributed collaborative learning environment. Retrieved June 2003 from http://www-ic2.univ-lemans.fr/ george/publications/george aied99.pdf

Georgiadou, E., \& Economides, A.A. (2000). Evaluation factors of educational software. Proceedings IEEE, International Workshop on Advanced Learning Technologies, pp. 113-116.

Georgiadou, E., Economides, A.A., Michailidou, A. \& Mosha, A. (2001). Evaluation of online educational software designed for the purpose of teaching programming. Proceedings of the WebNet 2001 Conference on the WWW and Internet. AACE.

Holst, S., \& Holmer, T. (2000). Continuous evaluation of web-based cooperative learning: The conception and development of an evaluation toolkit. Retrieved June 2003 from http://newmedia.colorado.edu/cscl/171.pdf

Jackson, R.L. \& Fagan, E. (2000). Collaboration and learning within immersive virtual reality. Proceedings of the Third international Conference on Collaborative Virtual Environments, pp 83-92, ISBN 1-58113-303-0, ACM Press.

Kauffman, J., \& Willis, S.K.T. (1999). Beginning ASP databases. Wrox Press ISBN 1-861002-7-26.

Michailidou, A., \& Economides, A.A. (2002). Elearn: A collaborative educational virtual environment. Proceedings of ELearn, World Conference on E-Learning in Corporate, Government, Healthcare, \& Higher Education, October 1519, pp. 690-697. AACE. 
Michailidou, A., Economides, A., \& Georgiadou, E. (2001). Collaborative virtual environments and their usage in educational procedure. Analysis and comparison. Proceedings of the conference New Technologies in Education and Distance Education, June 2001, Krete, Greece, pp. 130-142.

Micropoulos, T.A., Chalkidis, A., Katsikis, A., \& Emvalotis, A. (1998). Students' attitudes towards educational virtual environments. Education and Information Technologies, 3 pp. 137-148.

Micropoulos, T.A., Chalkidis, A., Katsikis, A., \& Kossivaki, P. (1997). Virtual realities in environmental education: the project LAKE. Education and Information Technologies, 2 pp. 131-142.

Nunes, M.A.S.N., Dihl, L.L., Fraga, L.M., Woszezenki, C.R., Oliveira, L., Francisco, D.J., Machado, G.D.J., Nogueira, C.R.D., \& Notargiacomo, M.de G. (2002, April). Animated pedagogical agent in the intelligent virtual teaching environment. Interactive Educational Multimedia, 4, pp. 53-60.

Pfister, H., Wessner, M., Holmer, T., \& Steinmetz, R. (1999). Evaluating distributed computer-supported cooperative learning (D-CSCL): A Framework and some data. Proceedings of the $2^{\text {nd }}$ international conference on New Learning Technologies (NLT99). August 30-31 1999, University of Berne, Switzerland, pp. 234-241.

Redfern, S., \& Naughton, N. (2002). Collaborative Virtual Environments to Support Communication and Community in Internet-Based Distance Education, Journal of Information Technology Education, Volume 1, No. 3.

\section{Biographies}
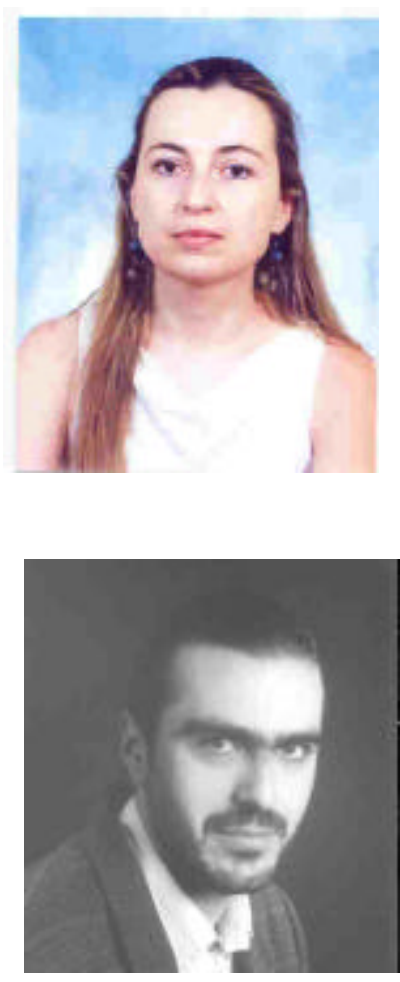

Anna Michailidou holds a M.Sc. in Information Systems from the University of Macedonia, Greece. She is a teacher of computer science in secondary education. Her M.Sc. thesis was about Virtual Educational Environments that support collaboration. She has also participated as a research scientist in a project funded by the Greek Ministry of Education concerning the usage of new technologies in secondary education. In particular, the theme of her work was educational software for teaching computer science. Finally, she is the leading author of an article in an international conference in Montreal, Canada and in Crete, Greece and part of a publishing team of two articles at international conferences (Orlando, Korea). The above articles concerned Collaborative Virtual Educational Environments and Evaluation Factors of Educational Software.

Dr. Anastasios A. Economides received the Diploma degree in Electrical Engineering from Aristotle University of Thessaloniki, in 1984. Holding a Fulbright and a Greek State Fellowship, he received a M.Sc. and a Ph.D. degree in Computer Engineering from the University of Southern California, Los Angeles, in 1987 and 1990, respectively. He is currently an Assistant Professor and Vice-Chairman in the Information Systems Postgraduate Program at the University of Macedonia, Thessaloniki, Greece. He is the Director of CONTA (COmputer Networks and Telematics Applications) Laboratory and Coordinator of several projects on Tele-education, Educational Technology and Training Trainers. His research interests are in the area of Computer Networks, Teleeducation and Educational Technology. He has published over 30 papers on Tele-education and Educational Technology. 